\title{
Article \\ Mechanical Strength Characterization of Plastic Fiber Reinforced Cement Concrete Composites
}

\author{
Sivakumar Anandan * ${ }^{(D)}$ and Majed Alsubih \\ Department of Civil Engineering, College of Engineering, King Khalid University, Abha 61421, Saudi Arabia; \\ malsubih@kku.edu.sa \\ * Correspondence: ksiva@kku.edu.sa
}

check for updates

Citation: Anandan, S.; Alsubih, M. Mechanical Strength Characterization of Plastic Fiber Reinforced Cement Concrete Composites. Appl. Sci. 2021, 11, 852. https://doi.org/ 10.3390/app11020852

Received: 8 December 2020

Accepted: 13 January 2021

Published: 18 January 202

Publisher's Note: MDPI stays neutral with regard to jurisdictional claims in published maps and institutional affiliations.

Copyright: (c) 2021 by the authors. Licensee MDPI, Basel, Switzerland. This article is an open access article distributed under the terms and conditions of the Creative Commons Attribution (CC BY) license (https:/ / creativecommons.org/licenses/by/ $4.0 /)$.
Featured Application: The futuristic application of plastic waste beneficiation and its recycling in concrete production provides a niche area of safe disposal without polluting the environment.

\begin{abstract}
The reinforcing efficiency of plastic fibers obtained from shredded plastic waste was tested in plain concrete mixes and experimentally verified in this study. Plastic fibers up to $0.15 \%$ $\mathrm{V}_{\mathrm{f}}$ were added to the design concrete mix to assess the fiber effectiveness in terms of improved load carrying capability of various plastic fiber incorporated concrete composites. The effects of plastic fibers distributed homogenously in the entire depth of concrete and confined in the tension zone were evaluated in flexural bending properties. Mechanical strength properties were evaluated for two different types of concrete containing (i) plastic fibers added homogenously throughout the entire depth of concrete and (ii) the plastic fibers confined in the tension zone only. Flexural bending parameters such as toughness, residual strength, crack width, post-peak drop load resistance, and fiber performance index of various plastic fiber substituted concrete mixes were tested in compressive and flexural bending to assess the fiber reinforcing efficiency. Test results indicated that the plastic fibers added in tension zone confinement exhibited higher flexural strength $\left(5.26 \mathrm{~N} / \mathrm{mm}^{2}\right)$ improvements compared to homogeneously distributed concrete systems. Flexural bending characteristics in terms of absolute toughness and post peak strain softening were found to be appreciably higher $(132 \%)$ in tension zone confined plastic fiber concretes compared to homogeneous fiber concrete systems.
\end{abstract}

Keywords: plastic fibers; tension zone; post-crack toughness; residual strength; strain hardening

\section{Introduction}

Plastic waste disposal is a major environmental concern in many under-developed countries and there is an urgent need to find a viable disposable solution. It is well known that most of the plastic waste generated is primarily discarded from domestic use such as soft drink plastic cans and canned mineral water bottles. Compared to other types of plastic waste generated, the plastic bottle refuse from domestic household applications has become a huge solid waste disposal problem. Fiber reinforcements are generally used for special concrete applications wherein short discrete fibers are used as additional reinforcing material. The fibers are added in low volume (less than $2 \% \mathrm{~V}_{\mathrm{f}}$ ) to that of the total volume of concrete in order to improve the hardened concrete properties. Compared to traditionally used steel and polymeric fibers in concrete applications, the use of shredded waste plastic bottles as fibers can serve as an alternative solution since they are obtained from the domestic plastic waste disposal. A more detailed review on the various recycled plastic wastes on the improvement of fresh and hardened concrete properties has been studied [1]. Hence, plastic waste disposal has emerged as a challenging task for environmentalists to identify a safe reuse technique without polluting the environment. In recent research studies, plastic wastes have been safely used as inert filler materials in concrete 
production. Effective utilization of plastic waste can save the surrounding environment from pollution and can beneficially increase the plastic waste consumption in concrete systems. There have been few research works to beneficiate the plastic waste addition in concrete systems and some of the salient works are reviewed further. A new type of plastic concrete was developed using Polyvinyl alchol (PVA) fibers and an optimal fiber volume fraction of $0.2 \%$ addition was found to increase the compressive strength, splitting strength, ductility, and toughness without decreasing the elastic modulus [2]. The reliable application of flexible plastic fiber concrete was tested in the tunnel lining to prevent the damage caused by the fault movement. Test results indicated that the plastic strain added near the flexible joints in concrete provides favorable ductility and toughness properties, leading to less deformation. The beneficial use of discarded synthetic plastic wastes was studied to analyze the failure mechanisms in compression, splitting failure, and in flexural bending modes [3]. Plastic materials have been widely used in soft drink bottles and are most commonly used as packaging materials for processed food products. In addition, the plastic containers are typically used for industrial liquid storageas a thermal resistant sealant material and in many household wrapping consumables. There have been several treatment methods practiced for the safe disposal of synthetic wastes, but most treatment methods have not been effective in terms of excessive plastic waste generation. In another study, the mechanical properties of shredded plastic Polyethylene terephthalate (PET) were investigated as partial replacement materials for aggregate. Experimental results on the mechanical properties of concrete and mortar were found to be typically altered with the size of PET flakes [4-6]. In another study, waste plastic was used as an aggregate replacement for partial replacement of sand at $0 \%, 10 \%, 15 \%$, and $20 \%$ and proved to be beneficial in improving the compressive properties as well as crack arresting mechanism. However, with an increase in percentage replacement of plastic aggregate, he compressive and flexural strength, modulus of elasticity, and bond strength were found to be affected [7]. A comprehensive review on the various types of wastes was conducted and the effect of various types of fibers such as PET, rubber tires, and glass was analyzed [8]. Studies were also conducted on using recycled plastic as aggregate (RPA) fillers up to 70\% replacement for conventional sand and quarry dust. The test results suggested that the RPA aggregate bonding with filler materials enhanced the compressive properties, and the angular particle of quarry fines was found to provide better strength properties than normal sand fillers. The reduction in compressive strength for RPA was noted and was primarily due to weak interface properties, RPA aggregate, and cement mortar due to hydrophobic surface characteristics of the plastic aggregates [9].Three different types of recycled waste plastic have been used as partial replacement for conventional aggregates. The mechanical properties were found to be affected with large volume replacements of RPA [10]. In recent times, a most versatile technique for plastic disposal is to recycle them as shredded plastic fiber, which, in turn, is used as matrix reinforcement for concrete. Steel fibers have been typically used in many research studies due to high modulus and large tensile strength [11]. Nowadays, synthetic fibers are becoming more popular for its reinforcing ability in the production of lightweight precast concrete elements. Fiber performance improves in a concrete matrix with a maximum fiber volume fraction up to $1 \%$ [12]. With increasing fiber volume fraction, the concrete mix becomes too stiff, resulting in a harsh mix and more void formation, leading to poor concrete strength. The replacement of steel fibers with the polypropylene fibers at a rate of $0.2 \%$ by volume fraction improved the overall mechanical properties of the concrete. Many research investigations have shown that fiber pullout strength is primarily dependent on its embedment length and the volume fraction of fibers available at the crack front. [13]. Experimental investigations on metalized plastic waste (MPW) generated from discarded food packaging were analyzed in another study [14]. The MPW films were shredded into the macro fibers of varying lengths of $5 \mathrm{~mm}, 10 \mathrm{~mm}$, and $20 \mathrm{~mm}$ and mixed into the concrete by volume fractions from $0 \%$ to $2 \%$. The test results showed excellent improvement of the impact resistance by concrete containing MPW fibers of $20 \mathrm{~mm}$ length compared to the conventional concrete. In another typical study, the im- 
pact resistance of concrete composites incorporating metalized plastic fibers in palm oil fuel ash (POFA) were investigated [15]. Concrete mixes were proportioned with $20 \mathrm{~mm}$ plastic fibers and added up to $1.25 \%$ by volume of concrete. Test results were indicative of the improved impact resistance and strength properties of plastic fiber incorporated hardened concrete. The effect of waste plastic fibers on the behavior of self-compacting concrete was investigated to evaluate the resistance of chloride attack [16]. Test results showed the integrity of fibers in crack inhibition and thereby provide good chloride ingression into the concrete surface.

Fiber addition does marginally improve the pre-peak strain hardening region with an appreciable increase in the elastic modulus. The addition of steel fibers has shown a maximum increase in compressive strength up to 15\% [17]; however, an appreciable increase in bond strength and toughness was noted with the addition of steel fibers [18]. The maximum volume fraction of fibers at the crack plane plays an important role in stable crack growth formation. Many investigations have proven the beneficial addition of high modulus fiber on the overall improvement in strength, ductility, toughness, and durability [19]. The basic fiber mechanism is to prevent the crack origination and propagation. The use of high strength fibers at a large volume fraction does possess relative advantages on the flexural and tensile strength $[20,21]$. The use of thermosetting plastic waste as an admixture can be used to produce lightweight concrete, but the reduction in compressive strength was noticed [22]. A review of the various literature has provided the basic mechanical properties of plastic fiber addition in concrete. Limited studies have been conducted in the past to analyze the composite performance of plastic fibers to evaluate the synergistic interaction in the cementitious matrix. This study was primarily aimed at exploring the beneficial aspects of plastic fiber addition on the compressive and flexural properties of a concrete system. Characteristic evaluations on the fiber performance in brittle concrete with respect to mechanical strength gain and toughness were studied. The present study was also more focused on determining the fiber performance index in a homogeneous fiber concrete system than that of tension zone confined plastic fiber reinforcement.

\section{Problem Statement}

The present study focused on producing plastic fiber reinforced concrete composites that can provide improved post elastic deformation characteristics in order to control the sudden failure by ductile yielding.

\section{Materials and Methods}

\subsection{Materials and Properties}

Concrete mixes chosen for this study were manufactured using locally available basic raw materials free from chlorides and sulfates. Cement of 43 grade, fine sand obtained from nearby river sediments, and crushed granite rocks as aggregates were used in the concrete production. The detailed properties of various constituent materials are provided in Table 1.

Table 1. Properties of the concrete ingredients.

\begin{tabular}{cccc}
\hline Properties & Cement & River Sand & Crushed Aggregate \\
\hline Grade & 43 & $4.75 \mathrm{~mm}$ (passing) & $12.5 \mathrm{~mm}$ (passing) \\
\hline Specific gravity & 3.12 & 2.45 & 2.61 \\
\hline Average particle size $(\mu \mathrm{m})$ & 42 & & \\
\hline Fineness modulus & & 2.36 & 6.45 \\
\hline Bulk density $\left(\mathrm{kg} / \mathrm{m}^{3}\right)$ & 3125 & 2205 & 2415 \\
\hline
\end{tabular}




\subsection{Plastic Fibers}

Used waste plastic bottles collected from domestic discards, as shown in Figure 1, were shredded by a mechanical cutting machine and made as thin flat fiber sections, as shown in Figure 2.

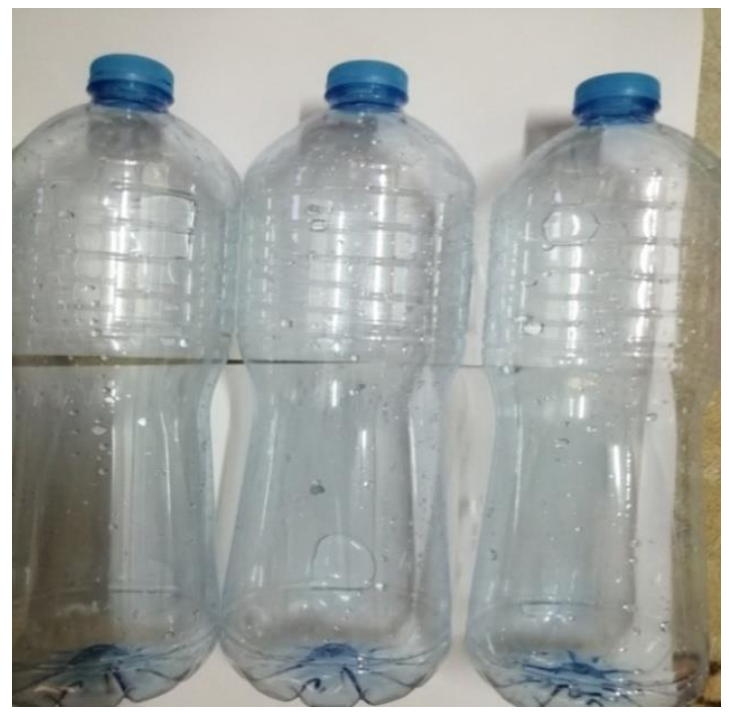

Figure 1. Waste plastic bottles.

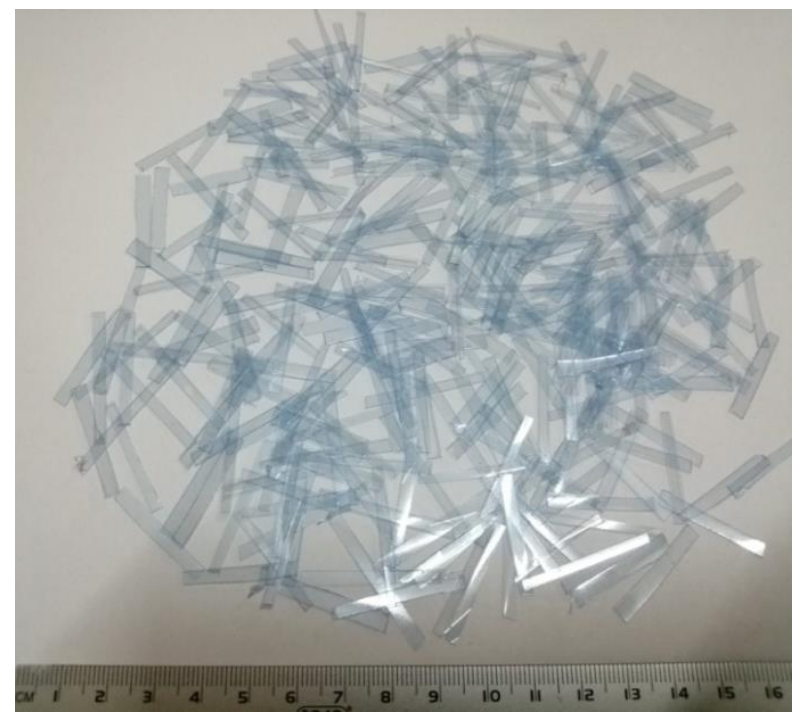

Figure 2. Fibers obtained from the shredded plastic bottles.

Short cut flat plastic fibers with an average length of $15 \mathrm{~mm}$ were used in this study to evaluate the fiber performance in concrete. The basic properties of plastic fibers used in this study are provided in Table 2 and these fibers were added in concrete homogenously by dry mixing in the concrete ingredients. This ensures fiber segregation and balling effects while being mixed with water. 
Table 2. Properties of the plastic fibers used in this study.

\begin{tabular}{|c|c|c|c|c|c|c|}
\hline Type of Fiber & $\begin{array}{l}\text { Specific } \\
\text { Gravity }\end{array}$ & $\begin{array}{l}\text { Average } \\
\text { Length } \\
(\mathrm{mm})\end{array}$ & $\begin{array}{l}\text { Average } \\
\text { Width } \\
\text { (mm) }\end{array}$ & $\begin{array}{l}\text { Aspect } \\
\text { Ratio } \\
\text { (L/W) }\end{array}$ & $\begin{array}{c}\text { Yield } \\
\text { Strength } \\
\left(\mathrm{N} / \mathrm{mm}^{2}\right)\end{array}$ & $\begin{array}{c}\text { Failure } \\
\text { Strain } \\
(\%)\end{array}$ \\
\hline $\begin{array}{l}\text { Shredded plastic } \\
\text { waste fibers-flat } \\
\text { cross section type }\end{array}$ & 0.92 & 15 & 1.13 & 13.27 & 31.5 & 52 \\
\hline
\end{tabular}

\subsection{Fresh Concrete Design}

In order to study the reinforcing characteristics of plastic fibers in concrete, different fiber proportions were considered. The basic compositions of concrete materials were varied to obtain the required design concrete strength. Trial concrete mixes were proportioned as given in Table 3 to obtain the desired concrete strength and further investigations were carried out using these concrete mixtures.

Table 3. Basic concrete proportions used in the experimental study.

\begin{tabular}{cc}
\hline Mix Constituents & Design Concrete-30 N/mm $\mathbf{~}^{\mathbf{2}}$ \\
\hline Cement $\left(\mathrm{kg} / \mathrm{m}^{3}\right)$ & 342 \\
\hline Sand $\left(\mathrm{kg} / \mathrm{m}^{3}\right)$ & 694 \\
\hline Coarse Aggregate $\left(\mathrm{kg} / \mathrm{m}^{3}\right)$ & 1194 \\
\hline $\mathrm{w} / \mathrm{c} \mathrm{ratio}$ & 0.43 \\
\hline Water $\left(\mathrm{kg} / \mathrm{m}^{3}\right)$ & 175 \\
\hline Superplasticizer $\left(\mathrm{kg} / \mathrm{m}^{3}\right)$ & $1.2 \%$ \\
\hline Trial Concrete compressive strength $($ after 28 days curing) & 22.3 \\
\hline Note: Basic mix proportions for reference concrete without plastic fibers.
\end{tabular}

A total of seven different concrete mixes were cast; out of which a reference concrete mixture (without fibers) designated as RCM1 and the remaining six fiber concrete mixes were designated as PFC followed by fiber proportion $(0.05,0.10,0.15)$ and distribution $(\mathrm{H}$ or $\mathrm{T})$. The detailed fiber proportions and the various fiber concrete mixes tested are provided in Tables 4 and 5 . The different fiber proportions for preparing the plastic fiber concrete mixes are given in Table 4. It can be noted that the plastic fibers were taken in terms of total volume fraction of concrete, and finally the required quantity was arrived at in terms of weight fraction.

Table 4. Fiber proportions used in this study.

\begin{tabular}{ccc}
\hline S. No. & $\begin{array}{c}\text { Volume Fraction of Plastic Fibers } \\
\left(\mathbf{V}_{\mathbf{f}} \text { in } \mathbf{\%}\right)\end{array}$ & $\begin{array}{c}\text { Weight of Plastic Fibers Added for } \\
\left.\mathbf{1 ~ m}_{\mathbf{3}} \mathbf{~ o f ~ C o n c r e t e ~} \mathbf{~} \mathbf{k g}\right)\end{array}$ \\
\hline 1 & 0.05 & 0.46 \\
\hline 2 & 0.10 & 0.92 \\
\hline 3 & 0.15 & 1.38
\end{tabular}

Note: Volume fraction of fibers refers to \% by volume of concrete; weight fraction of fibers obtained in terms of density ratio of plastic to concrete (i.e., $24 \mathrm{KN} / \mathrm{m}^{3}$ ).

\subsection{Concrete Production}

Initially, the basic raw materials required for concrete (with calculated proportions), as given in Table 3, were added into a standard concrete mixer of $100 \mathrm{~kg}$ capacity and dry mixed initially for $2 \mathrm{~min}$. Furthermore, the required mix water and plasticizers (CERAPLAST-300) were added into the concrete mixer followed by the addition of plastic fibers. Workability agents in the form of plasticizers are typically added in high strength 
fiber concrete production. The wet mix is then transferred to the required molds and cast (as shown in Figure 3). After sufficient concealed curing (28 days), the hardened concrete specimens were tested according to compressive and flexural bending tests.

Table 5. Various plastic fiber concrete mixes tested.

\begin{tabular}{cccc}
\hline S. No. & Mix ID & Type of Concrete Mix & $\begin{array}{c}\text { Fiber Proportions } \\
\left.\mathbf{V}_{\mathbf{f}} \text { in } \mathbf{~}\right)\end{array}$ \\
\hline 1. & RCM-30 & Reference concrete & 0 \\
\hline 2. & PFC-05H & Plastic fiber-homogenous & 0.05 \\
\hline 3. & PFC-10H & Plastic fiber-homogenous & 0.10 \\
\hline 4. & PFC-15H & Plastic fiber-homogenous & 0.15 \\
\hline 5. & PFC-05T & $\begin{array}{c}\text { Plastic fiber-tension } \\
\text { confined }\end{array}$ & 0.05 \\
\hline 6. & PFC-10T & $\begin{array}{c}\text { Plastic fiber-tension } \\
\text { confined }\end{array}$ & 0.10 \\
\hline 7. & PFC-15T & $\begin{array}{c}\text { Plastic fiber-tension } \\
\text { confined }\end{array}$ & 0.15 \\
\hline
\end{tabular}

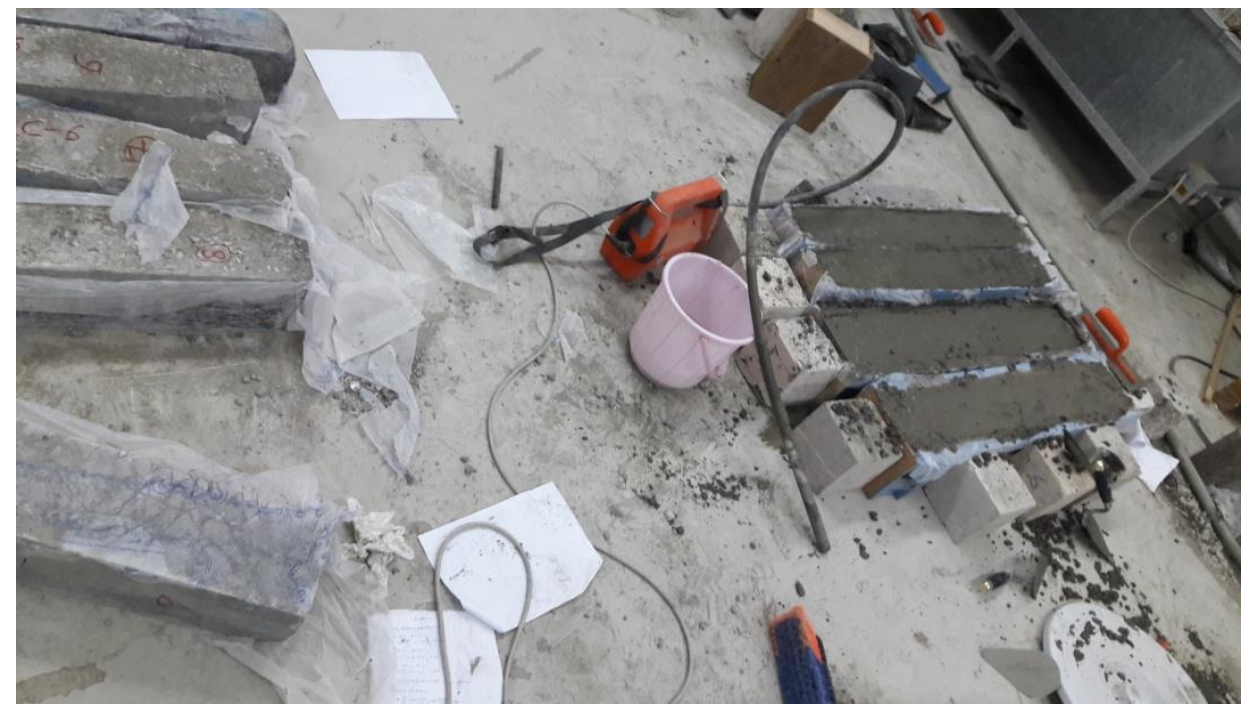

Figure 3. Controlled casting and sealed curing of concrete specimens.

\subsection{Experimental Methodology and Testing}

The experimental research consisted of investigating the properties of concrete substituted with plastic fibers at different volume fractions. Most importantly, the significance of this research consisted of evaluating the fiber reinforcing efficiency in terms of the distribution of discrete fibers as either homogeneous (full depth) or tension zone confined fiber reinforcement. The detailed experimental methodology carried out in this investigation is presented in the flow chart given in Figure 4.

\subsection{Experimental Testing}

Hardened concrete properties were tested according to the ASTM C-39 [23] testing methodology in order to determine the stress-strain characteristics of concretes. Compressive loading was applied in a compressive testing machine of $1000 \mathrm{KN}$ capacity. Compressive load versus linear strain of various fiber concrete specimens was determined using a compressometer fitted to the lateral sides $(10 \mathrm{~cm}$ gauge length $)$ of the cylindrical specimens of $150 \mathrm{~mm} \times 300 \mathrm{~mm}$. Flexural strength properties of concrete were evaluated 
using notched prism specimens of size $100 \mathrm{~mm} \times 100 \mathrm{~mm} \times 1000 \mathrm{~mm}$ with $10 \mathrm{~mm}$ notch depth and RILEM TC-34 [24] standard specifications was used for the flexural testing. The detailed experimental test setup is shown in Figures 5 and 6.

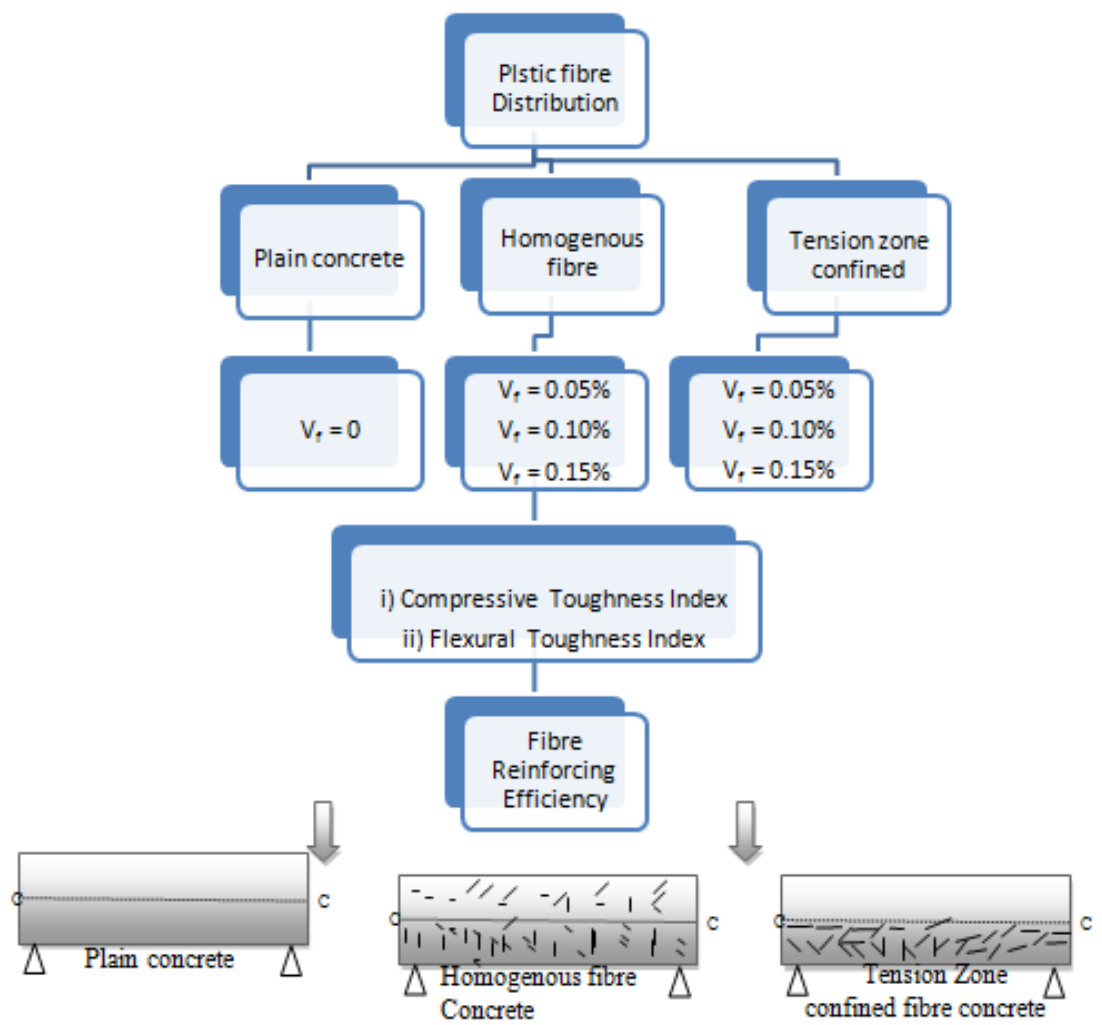

Figure 4. Experimental methodology and layered casting of plastic fibers.

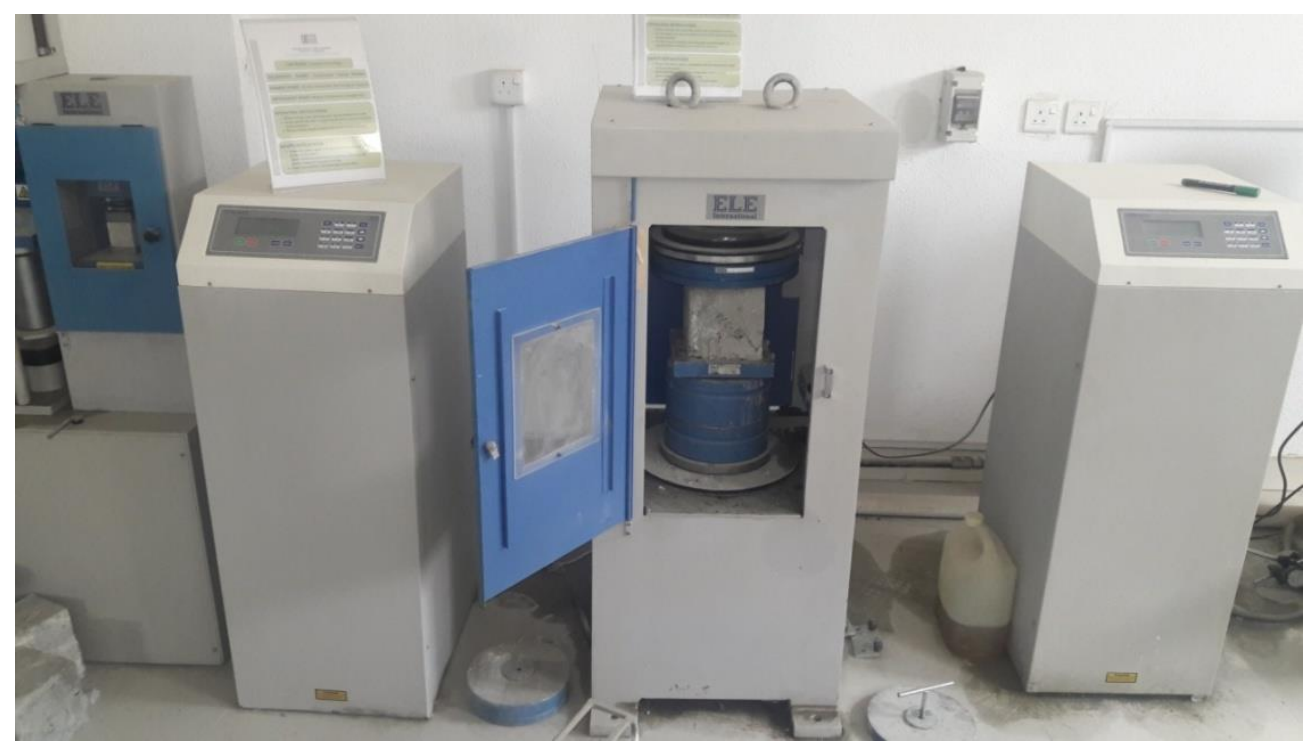

Figure 5. Compressive stress test setup. 


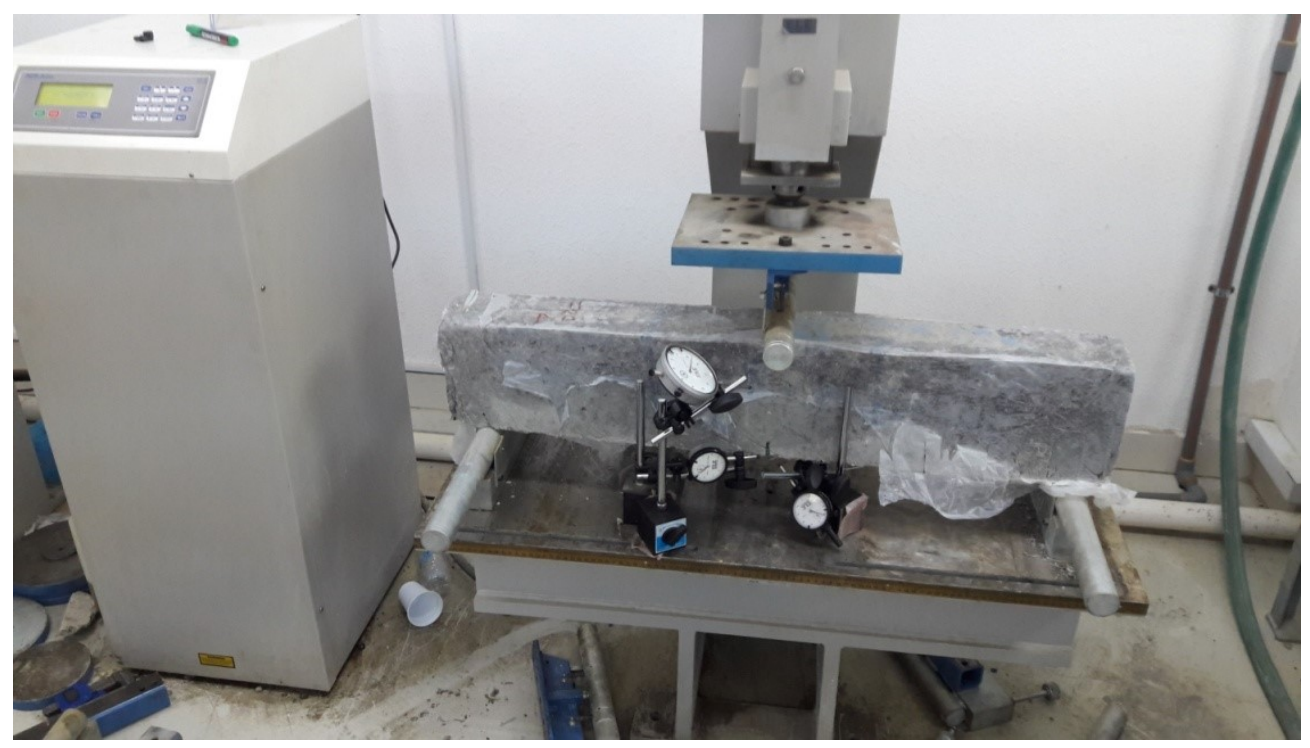

Figure 6. Flexural bending test setup.

From the experimental observations, the following measurements were used to quantify the test results:

\subsubsection{Compressive Test Measurements}

(a) Ultimate compressive strength-maximum peak strength of concrete.

(b) Residual strength-concrete specimens loaded at $95 \%$ of ultimate load and unloaded completely; then reloaded till failure to obtain the residual strength.

(c) Elastic modulus - the ratio of stress-strain value obtained from stress-strain plot.

(d) Pre-peak strain hardening toughness-the area under the stress-strain plot until the ultimate stress.

(e) Absolute toughness-the entire area under the stress-strain plot until failure of concrete.

(f) Post ultimate compressive toughness-the area under the stress-strain plot between the ultimate stress and complete failure.

(g) Compressive strength increase- the ratio of compressive strength of reference concrete to that of fiber incorporated concrete mixes.

(h) Compressive toughness increase- the ratio of absolute toughness of reference concrete (RCM-30) to that of plastic fiber concretes.

(i) Fiber performance index-the sum of compressive strength and absolute toughness increase of plastic fiber concretes to that of reference concrete.

\subsubsection{Flexural Test Measurements}

(a) First crack strength-the strength of concrete beam specimens at the first visible crack during loading.

(b) Flexural strength-the maximum ultimate strength of concrete beam.

(c) Crack width - the maximum crack opening at complete failure.

(d) Residual flexural strength capacity-concrete specimens loaded at 95\% of ultimate flexural load and unloaded completely; then reloaded until failure.

(e) Flexural toughness-area under the entire load-CMOD curves obtained from the various fiber concrete mixes.

(f) Post-peak drop load resistance - the sudden drop in load carrying capacity of the beam after the peak load.

(g) Flexural strength increase-the ratio of absolute toughness of reference concrete (RCM-30) to plastic fiber concretes.

(h) Fiber effective index - the sum of flexural strength increase and absolute toughness of plastic fiber concretes to that of reference concrete. 


\section{Results}

\subsection{Compressive Strength Evaluation}

The compressive strength test results for the fiber incorporated mixes with homogeneous fiber addition is presented to compare the effects of plastic fiber substituted concrete mixes to that of the reference concrete mix. Since the concrete is subjected to pure compressive force throughout the concrete specimen; the mechanism of fiber reinforcements in homogenously substituted concrete mixes is of importance. Hence, a reference concrete and three concrete mixes (PFC-05H, PFC-10H, PFC-15H) containing plastic fibers were tested for compressive performance. On the other hand, the concrete mixes PFC-05T, PFC-10T, and PFC-15T were not evaluated due to the non-significance of the confined tensioned plastic fibers in compressive performance. A maximum compressive strength up to $33.25 \mathrm{~N} / \mathrm{mm}^{2}$ with a $10 \%$ increase was noted with $0.15 \% \mathrm{~V}_{\mathrm{f}}$ substituted plastic fiber concrete mixes (PFC-15T) compared to the reference concrete (RCM-30). This increase in trend was noted in another study [25] where a maximum strength attainment up to $42.67 \mathrm{~N} / \mathrm{mm}^{2}$ was achieved for a high grade concrete. However, studies revealed that mortar strength enhancement with the addition of fibers derived from waste PET was optimal up to a maximum volume fraction and decreased with further increase in plastic fiber volume [26]. In order to assess the mechanistic action of plastic fibers in the compressive failure mode of concrete, various parameters were carefully evaluated as provided in Table 6. The wide range of compressive properties with the influence of plastic fibers to enhance the crack arresting properties is collectively provided in Table 6 . The influence of plastic fibers on the compressive strength variations of various concretes mixes are provided in Figure 7. Graphical trends clearly represent the influence of plastic fibers in the matrix as it controls the progress of compressive failure. Initially, the reference plain concrete (RC-30) without fibers showed a sudden failure without post peak controlled yielding, resulting in a sudden drop in load carrying capacity exhibiting brittle failure. This behavior was completely absent in the plastic fiber incorporated concrete mixes (PFC-05H) as the pre-peak strain hardening and post peak strain softening were well controlled by the presence of fibers during matrix cracking. This was clearly interpreted for all the fiber substituted concrete mixes and the post peak characteristics were well improved during the progress of strain energy released during the failure process. However, the presence of fibers had a greater role during the post-peak crack propagationas the crack growth is well controlled by the presence of plastic fibers. In the case of high fiber incorporated concrete mixes (PFC-15H), the increased fiber availability at the crack-opening mode envisages effective stress redistribution in the nearby crack vicinity.

Table 6. Compressive properties of various plastic fiber concretes.

\begin{tabular}{|c|c|c|c|c|c|c|c|c|c|}
\hline Mix ID & $\begin{array}{l}\text { Ultimate } \\
\text { Strength } \\
\left(\mathrm{N} / \mathrm{mm}^{2}\right)\end{array}$ & $\begin{array}{l}\text { Residual } \\
\text { Strength } \\
\left(\mathrm{N} / \mathrm{mm}^{2}\right)\end{array}$ & $\begin{array}{c}\text { Elastic } \\
\text { Modulus } \\
\left(\times 10^{3} \mathrm{~N} / \mathrm{mm}^{2}\right)\end{array}$ & $\begin{array}{c}\text { Pre-Peak Strain } \\
\text { Hardening } \\
\text { Toughness } \\
\text { (N-m) }\end{array}$ & $\begin{array}{c}\text { Absolute } \\
\text { Toughness } \\
\text { (N-m) }\end{array}$ & $\begin{array}{c}\text { Post } \\
\text { Ultimate } \\
\text { Toughness } \\
\text { (N-m) }\end{array}$ & $\begin{array}{c}\text { Strength } \\
\text { Increase } \\
(\%)\end{array}$ & $\begin{array}{c}\text { Toughness } \\
\text { Increase } \\
(\%)\end{array}$ & $\begin{array}{l}\text { Fiber Per- } \\
\text { formance } \\
\text { Index (\%) }\end{array}$ \\
\hline RCM-30 & 30.21 & 2.34 & 26.16 & 122.51 & 122.51 & 0 & - & - & - \\
\hline PFC-05H & 31.53 & 15.61 & 28.05 & 192.38 & 378.02 & 185.29 & 4.37 & 208.56 & 220.26 \\
\hline PFC-10H & 33.12 & 17.23 & 28.78 & 159.3 & 516.38 & 357.75 & 9.63 & 321.5 & 338.95 \\
\hline PFC-15H & 33.25 & 18.16 & 28.91 & 158.63 & 509.63 & 351 & 10.06 & 315.99 & 333.72 \\
\hline
\end{tabular}

Note: Test results denote the average of five concrete specimens tested for each concrete mix type. 


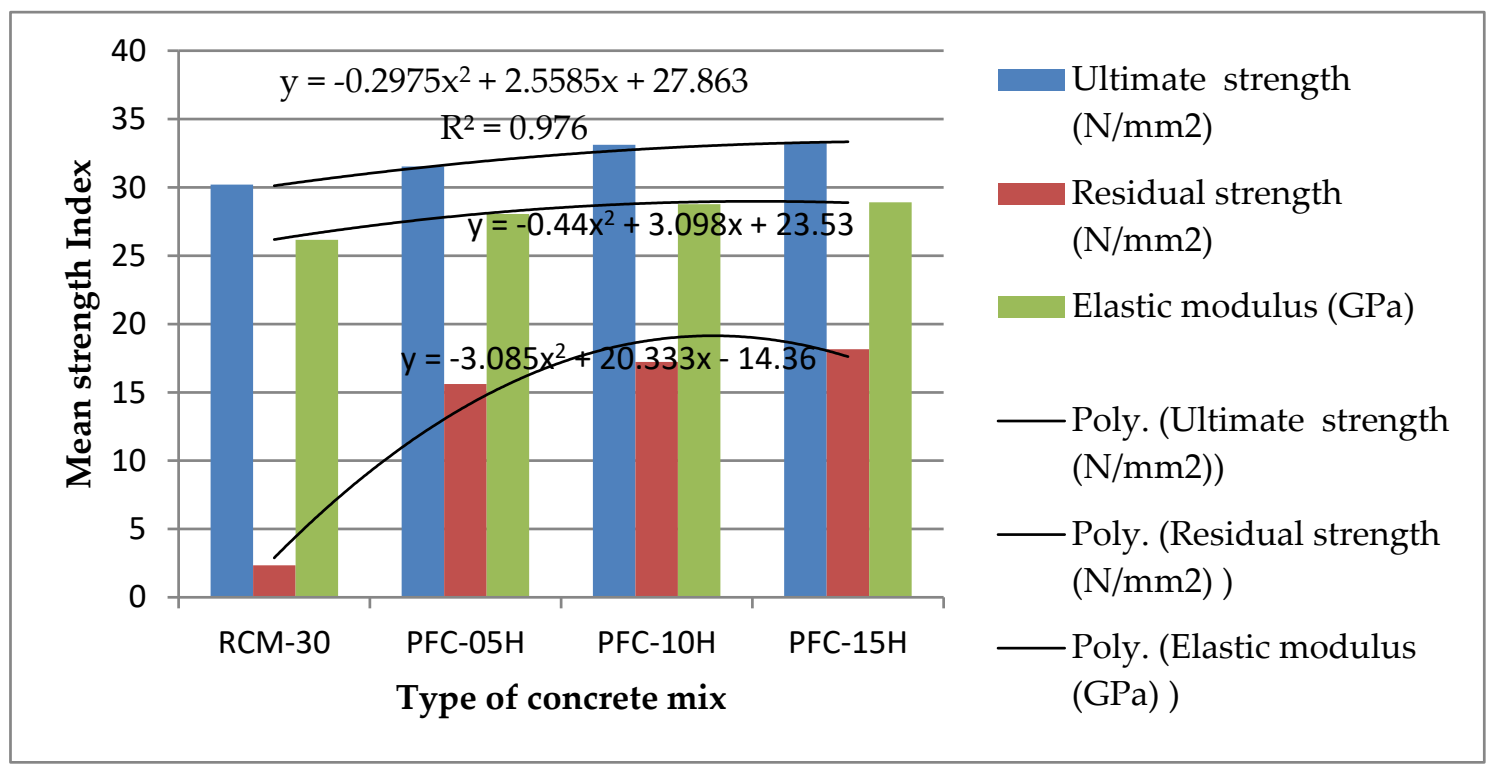

Figure 7. Characteristic compressive strength results of various plastic fiber concrete mixes.

Fibers did not bridge crack opening in compressive mode, but rather acted as stress redistribution for controlled failure process, since the failure mode in compression is not essentially due to fracture as it leads to crushing failure accompanied by shear plane along the diagonal tension. Hence, to validate the real merits of plastic fibers in the matrix, the load capacity of fiber concretes after multiple cracking needed to be tested. This was essentially measured using the residual capacity of fiber concrete mixes and the high fiber volume concrete mixes (PFC-15H) exhibited better strength capacity. The sudden drop in load for all fiber concrete mixes was drastically improved and better controlled with high fiber incorporated concrete mixes (PFC-10H and PFC-15H).

In order to assess the fiber influence on the concrete matrix, compressive test results obtained were systematically categorized to identify the significance of plastic fiber reinforcements. Compressive strength enhancements were favorably noticed in all fiber substituted concrete mixes as a result of the effective bonding of the fiber-matrix interface. As the fibers were not essentially stressed in compressive loading, the strength increase was only reasonably increased in all plastic fiber substituted concretes. However, compressive strength increase was reasonably improved compared to plain concrete specimens. In order to evaluate the fiber efficiency in the compressive direction, the study was intended to identify new strength parameters as determined from the compressive stress-strain properties of different concretes as described in the following sections.

\subsection{Ultimate Compressive Strength}

The ratio of ultimate compressive strength of plastic fiber concrete to that of plain concrete is defined as compressive strength ratio, which gives a direct measure of strength improvement. It can be noted that all plastic fiber incorporated concrete mixes showed a gradual increase in compressive strength compared to the reference concrete (as noted in Figure 7). Test results provided in Table 6 show that the plastic fiber addition showed a reasonable strength increase in the case of all three fiber concrete mixes. Among the various concrete mixes, a maximum compressive strength of $33.20 \mathrm{~N} / \mathrm{mm}^{2}$ with an increase up to $17.73 \%$ was noted in the case of the plastic fiber substituted concrete mix (PFC-15H).

\subsection{Residual Compressive Strength}

Residual strength is a measure of the strength carrying capacity of concrete specimens upon loading-unloading-reloading cycles until $95 \%$ of ultimate load capacity and then unloaded. Upon reloading the concrete specimens, the maximum strength regain until 
failure is termed as residual strength. A maximum residual strength of $18.16 \mathrm{~N} / \mathrm{mm}^{2}$ was noted in the case of concrete mix $(\mathrm{PFC}-15 \mathrm{H})$ containing $0.15 \% \mathrm{~V}_{\mathrm{f}}$ plastic fibers. Similarly, other plastic fiber substituted concretes exhibited an increased residual strength compared to plain concrete. Residual compressive strength is a characteristic property noticed in the case of fiber concretes as it refers to the ability of fiber concretes to resist load even after sustaining multiple fractures on the concrete surface. This is an important measurement of fiber concretes as the fibers present in the matrix envisages the strength retention capacity even after multiple fractures are sustained by the concrete specimens upon attaining ultimate load capacity. However, this residual capacity of plain concrete is completely absent as the concrete specimens sustain multiple fractures, and upon reloading, the stress capacity of failed specimens did not show any increment on the load carrying capacity. Hence, the plain concrete specimens failed suddenly upon re-loading, which exhibited poor residual strength. However, the test results represented in the characteristic curve signifies the residual strength capacity of all fiber concrete specimens.

\subsection{Elastic Modulus}

The stiffness of the composite can be better represented in terms of elastic modulus and the value was the maximum for the maximum fiber substitution at $0.15 \% \mathrm{~V}_{\mathrm{f}}$ of plastic fibers. In general, the elastic modulus of all plastic fiber substituted concrete mixes varied between $28.05 \mathrm{~N} / \mathrm{mm}^{2}$ to $28.91 \mathrm{~N} / \mathrm{mm}^{2}$ and showed gradual improvements compared to plain concrete. The substitution of plastic fibers in concrete mix (PFC-15H) improved the matrix strengthening and also achieved a maximum elastic modulus of $28.91 \mathrm{~N} / \mathrm{mm}^{2}$.

\subsection{Pre-Peak Strain Hardening Toughness}

It is well represented in stress-strain curve given in Figure 8 that the pre-peak strain hardened region of concrete specimens is a good indicator of continuous load carrying capacity with significant nonlinear region. Strain hardening of the concrete is a function indirect measure of micro-crack generation with the corresponding increase in the ultimate strength of the composite. However, compared to the reference concrete, the pre-peak and post peak characteristics of all plastic fiber substituted concrete mixes were appreciably improved. The overall toughness characteristics were primarily influenced due to the controlled failure offered by plastic fibers.

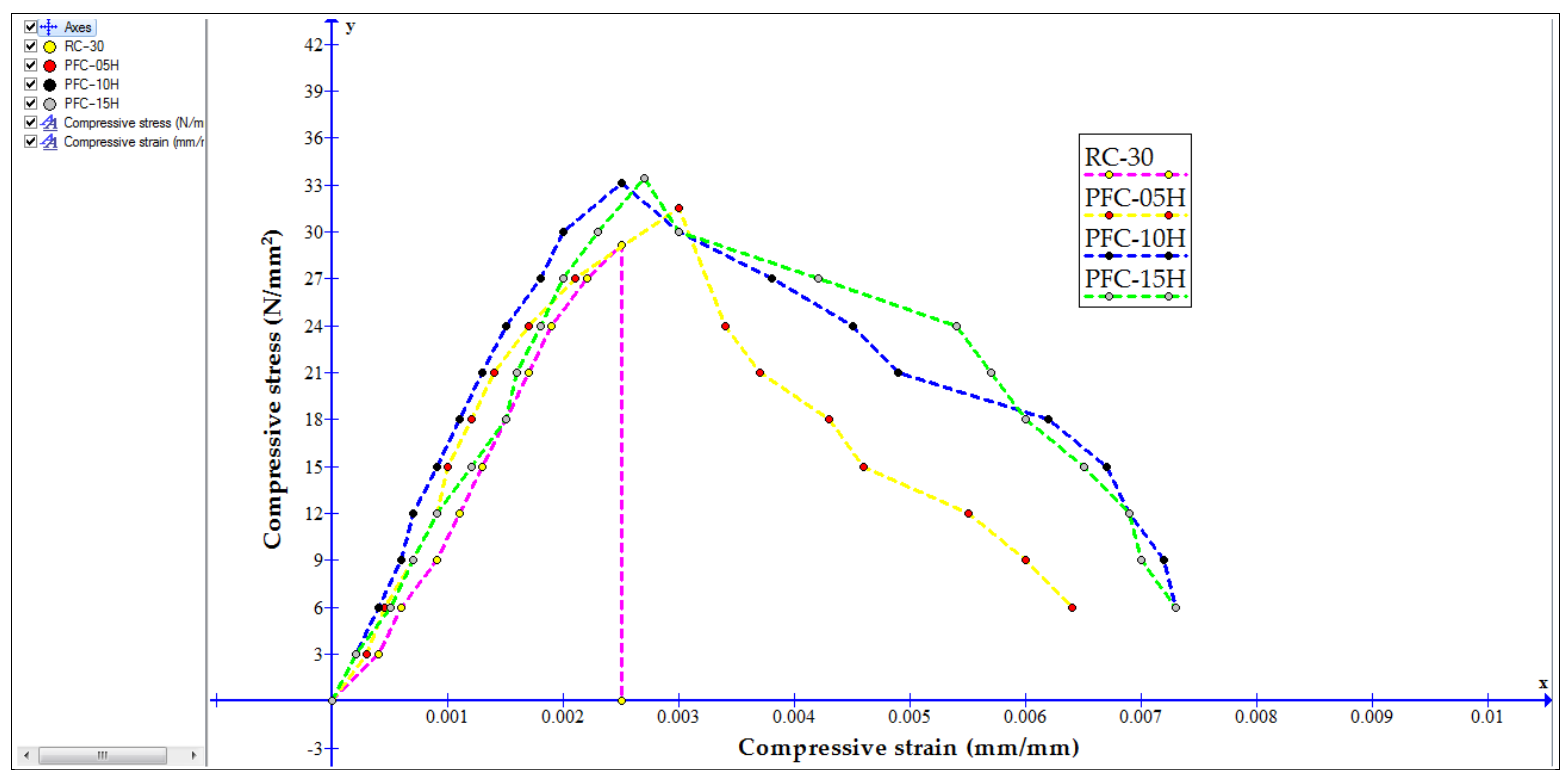

Figure 8. Stress-strain plot of various fiber concrete mixes in compression. 
The sudden failure in brittle plain concrete (RCM-30) was altered suitably in plastic fiber substituted concrete mixes. A maximum pre-peak strain hardening toughness of 192.38 N-m was observed for the PFC-05H concrete mix and a maximum post-peak toughness of $357.75 \mathrm{~N}-\mathrm{m}$ was observed in the case of the PFC-10H concrete mix. Nevertheless, a maximum overall toughness of $516.38 \mathrm{~N}-\mathrm{m}$ was obtained in the case of PFC-10H. The test results justify the fact that effective fibers in tension zone confined concretes were able to control the originating cracks in the matrix and at large deformation (post-peak), bridge the crack opening. Fibers present in the matrix tended to delay the crack origination and subsequently control the crack multiplication in the matrix, leading to improved first crack stress. Additionally, the overall toughness increase of $321.5 \%$ was noticed in the case of the PFC-10H concrete mix. Thus, the parameters measured in this study signify the importance of plastic fiber action in the matrix.

\subsection{Absolute Toughness}

The toughness obtained from the entire stress-strain curve of the concrete specimens provides the measure of energy absorbed during the progress of loading. The absolute toughness calculations for the various fiber concrete mixes are provided in the sample calculation shown in Figure 9. This parameter estimates the combined efficiency of fibers in pre-peak and post-peak toughness characteristics. Among the different plastic fiber concretes, the maximum absolute toughness of $516.38 \mathrm{~N}-\mathrm{m}$ was obtained in the PFC-10H concrete mix. The absolute toughness of all plastic fiber substituted concrete mixes was improved considerably and the relative percentage of increase in compressive toughness was above $200 \%$.

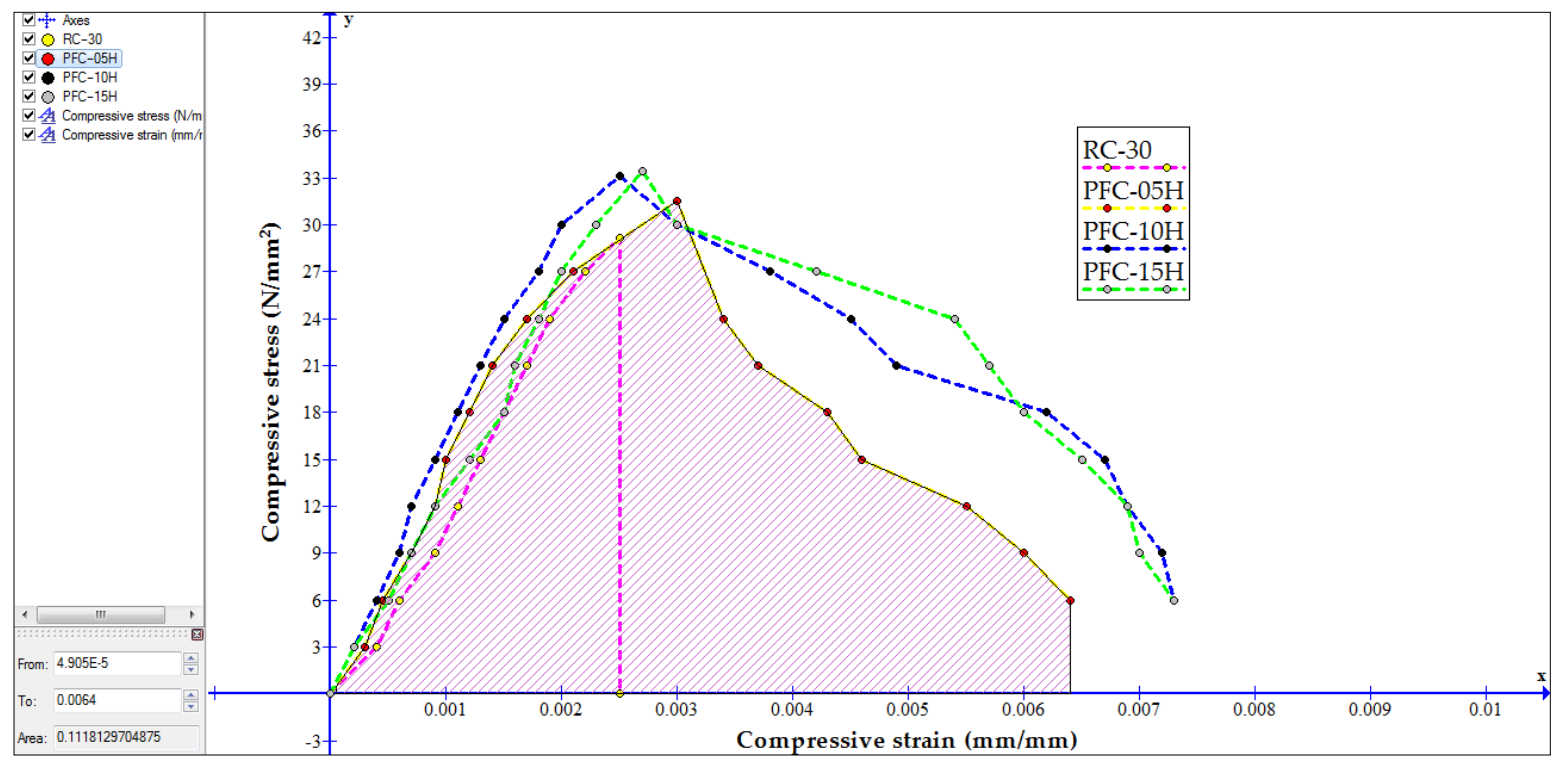

Figure 9. Absolute toughness calculation using a graph (shaded area) for various fiber concretes.

\subsection{Post-Ultimate Compressive Toughness}

The gradual decrease in the load carrying capacity of the concrete after peak stress was characterized by the significant drawdown of the stress-strain curve. The post ultimate toughness calculations for the various fiber concrete mixes are provided in the sample calculation as shown in Figure 10. In the case of all fiber substituted concrete mixes, the sudden drop in load capacity was controlled by the fiber bridging the cracks at non-steady crack growth propagation. However, the unstable crack growth after peak stress was well diminished with the addition of high fiber volume in the concrete matrix. This was 
evidently seen in the PFC- $15 \mathrm{H}$ concrete mix, which incorporated a high fiber volume $(0.15 \%$ $\mathrm{V}_{\mathrm{f}}$ ) of plastic fibers.

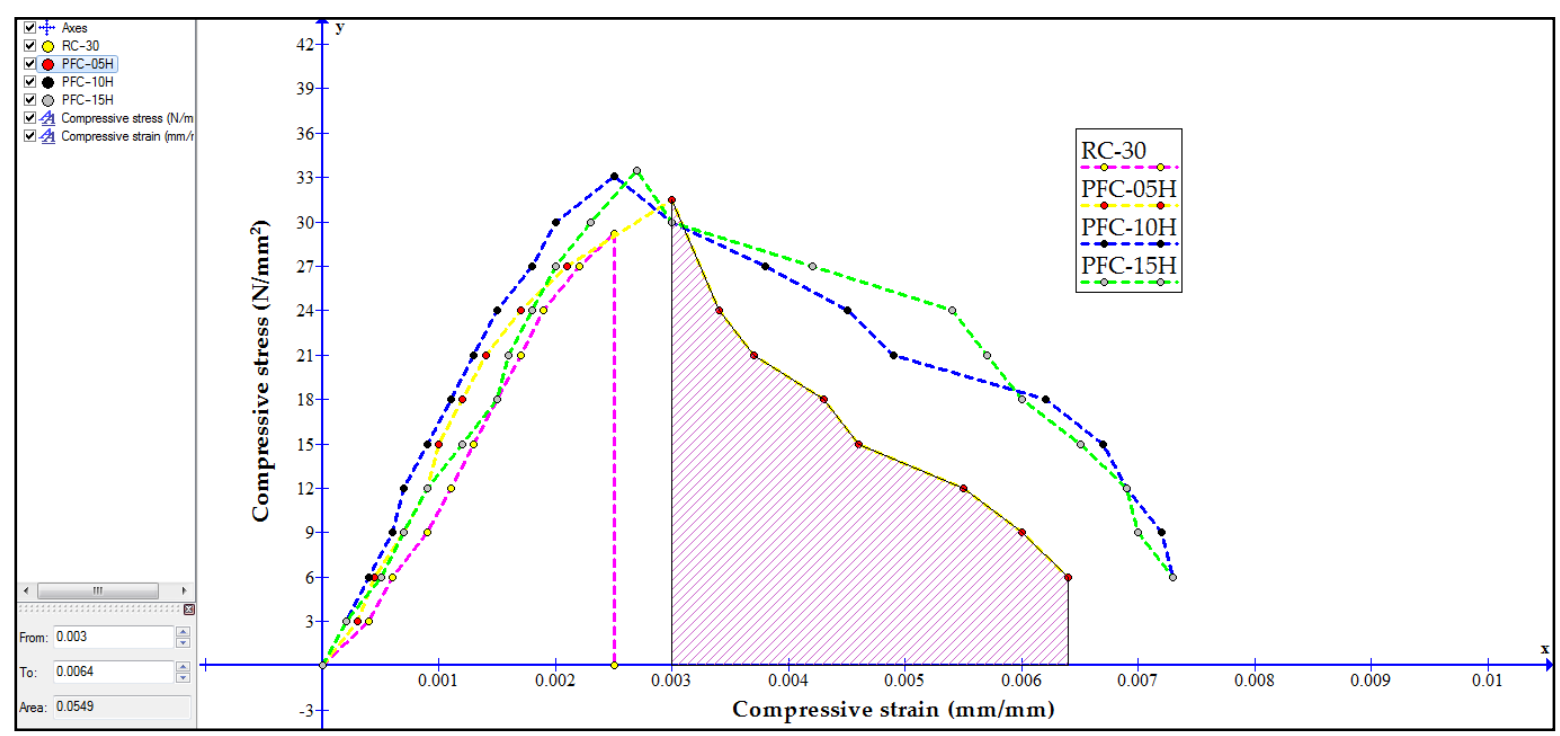

Figure 10. Post ultimate compressive toughness calculation using a graph (shaded area) for various fiber concretes.

\subsection{Compressive Strength Increase}

The ratio of the compressive strength of fiber concrete to that of the reference concrete is denoted as the compressive strength index. This gives the direct estimation of the increase in the compressive strength value in terms of the number of times of the reference concrete.As can be seen from Table 6, the strength index was a maximum $17.73 \%$ in the case of the high volume fiber concrete mixes (PFC-15H). However, the strength increase was gradual depending upon the increase in plastic fiber volume fraction and thereupon the strength increase was saturated upon reaching the maximum fiber volume fraction.

\subsection{Compressive Toughness Increase}

The post elastic deformation and the energy absorption capacity of fiber concrete mixes are commonly referred to as an indicator of toughness. The mean toughness values for various fiber incorporated concrete mixes are provided in Figure 11.

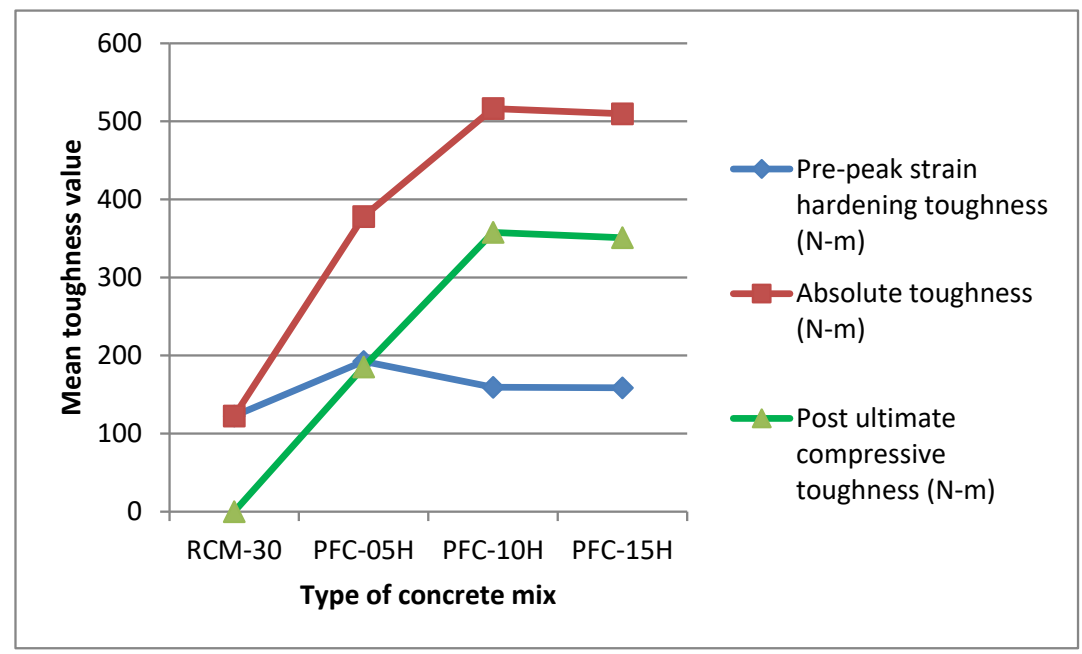

Figure 11. Mean compressive toughness performance values of various fiber concrete mixes. 
Failure accompanied by controlled crushing after attaining the ultimate strength in concrete is most desired in a ductile composite system. The inclusion of plastic fibers in concrete provided sufficient confinement during compressive forces due to the large strain at failure and thereupon providing the composite ductile failure mode. The increase in toughness (321.5\%) was phenomenal with the maximum fiber volume fraction up to $0.10 \%$ $\mathrm{V}_{\mathrm{f}}$. Delayed crack formation and propagation provided adequate build up in strain energy for reaching maximum stress capacity, and further upon, the fibers played a dominant role in gradual energy dissipation (by fiber straining) until complete failure.

\subsection{Fiber Performance Index}

The overall analysis of the compressive parameters as calculated from the stress-strain curve of the various reference/plain concrete and plastic fiber substituted concrete mixes indicates the performance measurements in compressive loading. The fiber performance index for various plastic fiber substituted concrete mixes is represented in Figure 12. The maximum fiber performance index (338\%) was observed at a high plastic fiber volume fraction of $0.1 \% \mathrm{~V}_{\mathrm{f}}$. It can be summarized from the test results that the post yielding characteristics of concretes were well controlled with the influence of plastic fibers in the matrix. Since the plastic fibers used in this study itself had a high plastic deformation capacity, their inclusion in concrete had positive effects on the controlled failure characteristics. The fiber substituted concrete mixes showed positive effects on the compressive toughness as the fiber enhanced the post peak strain-softening region of the concrete.

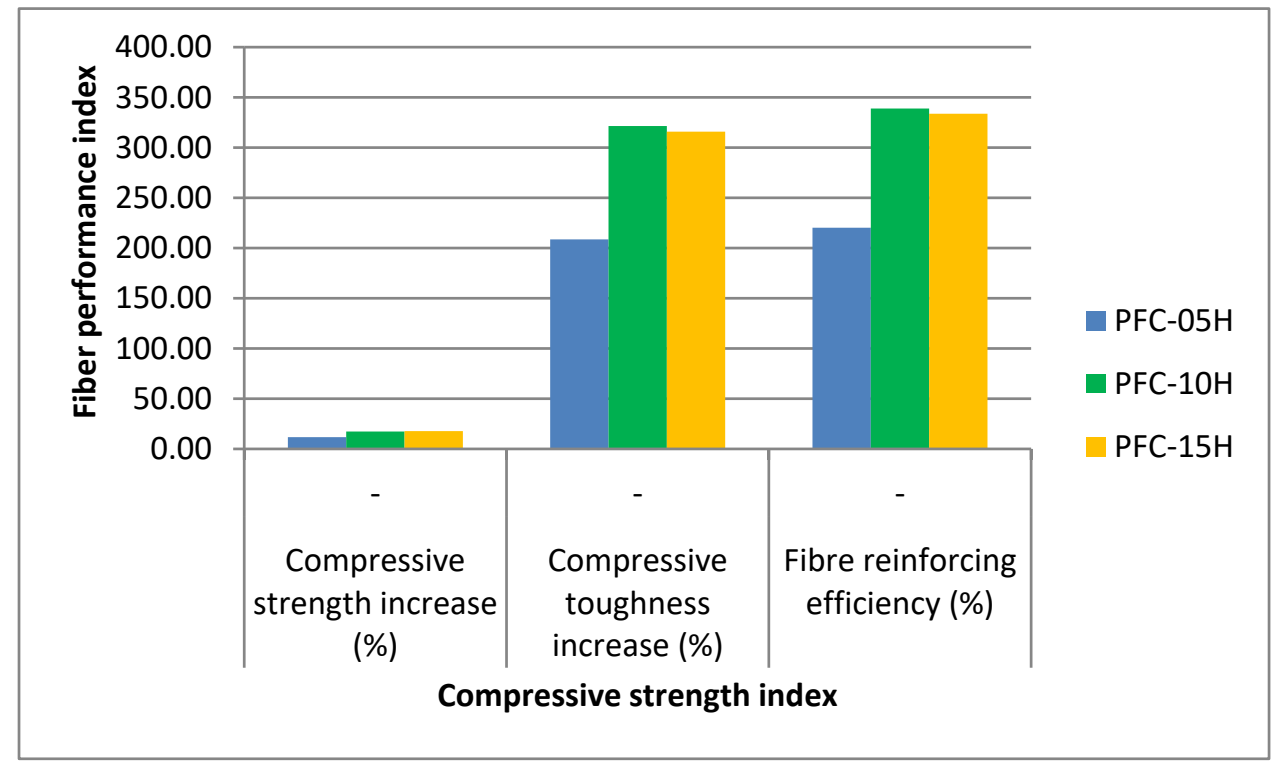

Figure 12. Relationship between the compressive strength index vs. fiber performance index.

\subsection{Flexural Characteristics}

The exclusive test parameters evaluated based on the flexural bending results are provided in Table 7 and the significant effects of randomly/homogenously distributed (full concrete volume) versus tension zone confined fiber concretes are discussed in this section. The fiber alignment showed significant effects on the stress sharing during flexural bending. Additionally, in this study, the effects of fiber alignment in the tension zone showed maximum improvements on the flexural bending accompanied by increased flexural stress capacity. The fiber reinforcements showed real merits in terms of load resistance upon cracking without any sudden drop in load resistance. The discrete plastic fibers distributed in the concrete matrix homogeneously and confined in the tension zone were systematically evaluated using different experimental parameters. The importance of plastic fibers was convincing in improving the first crack strength of plain concrete, which 
can be noted from the load-crack mouth opening displacement (CMOD) curves provided in Figure 13.

Table 7. Flexural evaluations of various plastic fiber incorporated concretes.

\begin{tabular}{|c|c|c|c|c|c|c|c|c|}
\hline Mix ID & $\begin{array}{c}\text { First Crack } \\
\text { Strength } \\
\left(\mathrm{N} / \mathrm{mm}^{2}\right)\end{array}$ & $\begin{array}{l}\text { Flexural } \\
\text { Strength } \\
\left(\mathrm{N} / \mathrm{mm}^{2}\right)\end{array}$ & $\begin{array}{c}\text { Crack } \\
\text { Width }(\mathbf{m m})\end{array}$ & $\begin{array}{l}\text { Residual } \\
\text { Flexural } \\
\text { Strength } \\
\text { Capacity } \\
\left(\mathrm{N} / \mathrm{mm}^{2}\right)\end{array}$ & $\begin{array}{c}\text { Flexural } \\
\text { Toughness } \\
\text { (N-m) }\end{array}$ & $\begin{array}{c}\text { Post } \\
\text { Peak-Drop } \\
\text { Load } \\
\text { Resistance } \\
(\%) \\
\end{array}$ & $\begin{array}{c}\text { Flexural } \\
\text { Strength } \\
\text { Increase } \\
\quad(\%)\end{array}$ & $\begin{array}{c}\text { Fiber } \\
\text { Effective } \\
\text { Index (\%) }\end{array}$ \\
\hline RCM-30 & 3.72 & 3.8 & 1.25 & 0 & 0 & 0 & - & - \\
\hline PFC-05H & 3.89 & 4.12 & 1.54 & 2.05 & 5.39 & 65.2 & 8.42 & 73.62 \\
\hline PFC-10H & 4.17 & 4.36 & 1.86 & 3.18 & 15.39 & 73.3 & 14.74 & 88.04 \\
\hline PFC-15H & 3.95 & 4.2 & 1.8 & 3.21 & 20.78 & 88.4 & 10.53 & 98.93 \\
\hline PFC-05T & 4.27 & 4.72 & 2.12 & 2.98 & 10.42 & 90.9 & 24.21 & 115.11 \\
\hline PFC-10T & 4.89 & 5.26 & 2.75 & 4.18 & 29.57 & 93.7 & 38.42 & 132.12 \\
\hline PFC-15T & 4.51 & 4.85 & 3.15 & 4.37 & 33.43 & 96.2 & 27.63 & 123.83 \\
\hline
\end{tabular}

Note: Test results denote the average of five concrete specimens tested for each concrete mix type.

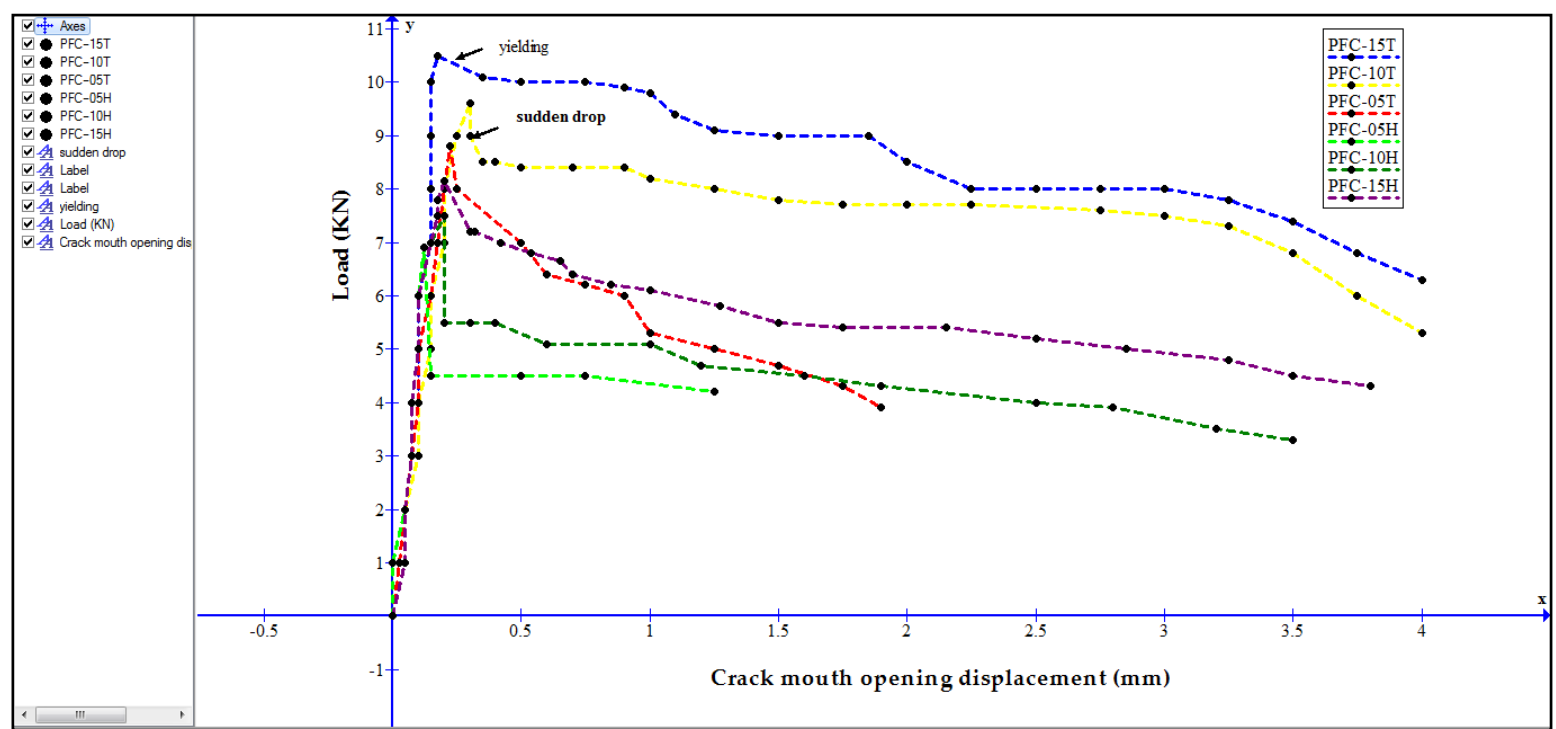

Figure 13. Load-CMOD curves for various plastic fiber incorporated concrete mixes.

Compared to full depth homogeneous fiber concrete, the first crack strength was evidently improved in the tension zone confined concrete. The maximum first crack strength of $4.89 \mathrm{~N} / \mathrm{mm}^{2}$ was observed for the PFC-10T concrete mix. It is well noted that the tension zone confined plastic fiber concrete consistently performed in all the flexural parameters evaluated. It is apparently evident that the flexural strength and residual flexural strength were increased in all tension zone confined fiber concretes compared to the homogenous fiber concretes. The effect of fiber alignment and confinement in tension zone had more pronounced effects on the flexural performance as the fibers were effectively strained along the bending axis. Hence, the stress transfer mechanism was readily shared in direct fiber alignment along the bending plane. A maximum flexural toughness of 33.43 $\mathrm{N} / \mathrm{mm}^{2}$ was obtained in PFC-15T and the toughness was notably increased at higher fiber volume fraction. It can be well derived from the test results that the toughness of higher volume fiber concrete is greatly improved. However, the confinement of fiber volume at lower fiber fraction showed consistent improvement on the overall flexural response 
compared to the homogenously distributed plastic fiber concrete systems. The maximum response values obtained from the various flexural parameters are discussed below

\subsection{First Crack Strength}

The variation of flexural strength properties are shown in Figure 14. Maximum first crack strength $\left(4.89 \mathrm{~N} / \mathrm{mm}^{2}\right)$ was obtained in the case of the PFC-10T concrete mix and the corresponding first crack strength value of $4.17 \mathrm{~N} / \mathrm{mm}^{2}$ was noted in PFC-H. Most significantly, all fiber substituted concrete mixes showed relative improvements in first crack strength compared to the reference concrete. This apparently shows that the effective fiber volume in tension zone confined concrete systems exhibited better performance compared to the homogeneously distributed fiber concretes. The first crack improvements were due to corresponding increase in matrix strengthening with an effective fiber placement along the bending plane. Hence, the test results are more convincing when the total fiber volume are effectively confined in the tension zone rather than distributed homogeneously in the entire depth of the concrete beam.

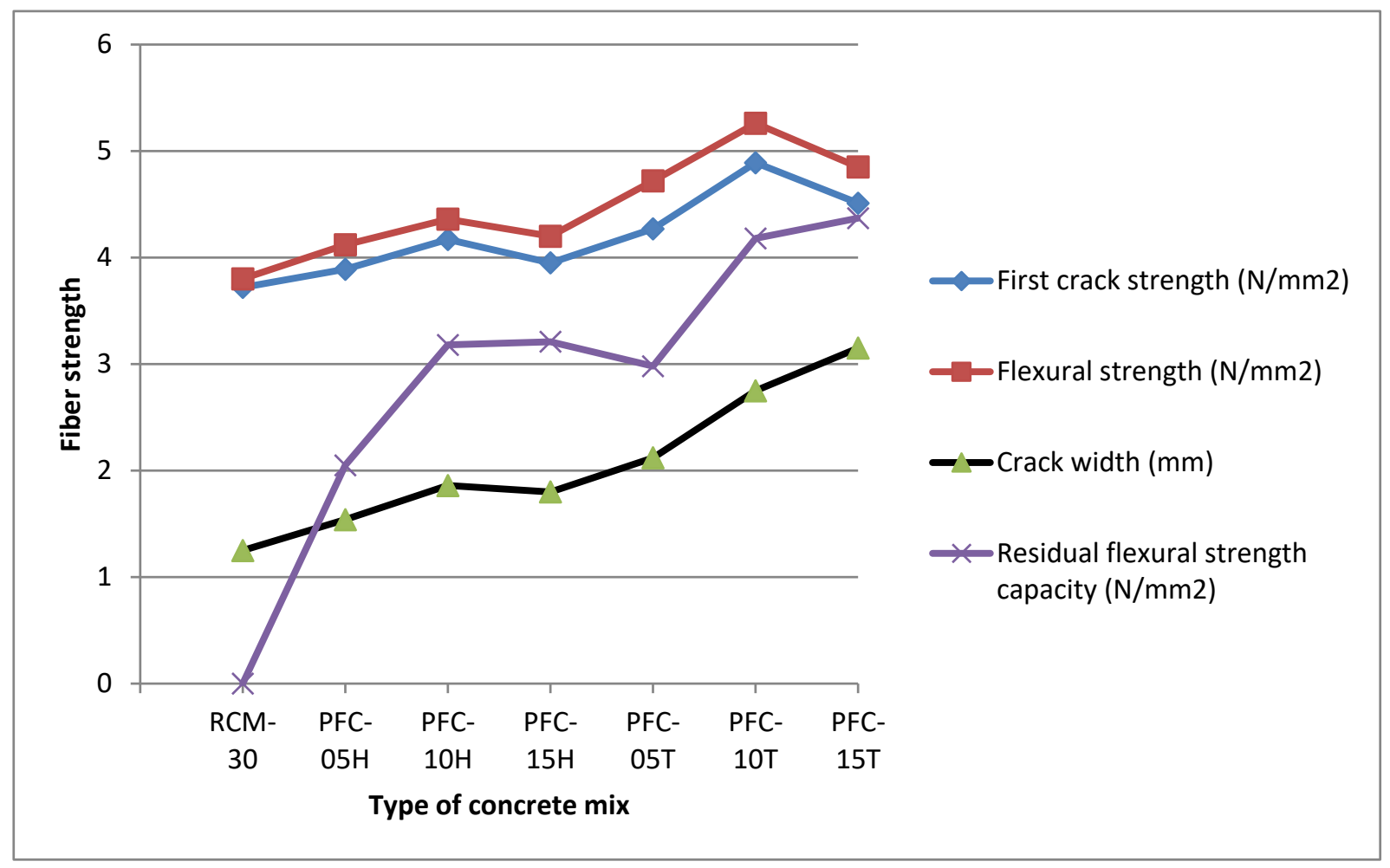

Figure 14. Variation of flexural strength parameters for various plastic fiber concrete mixes.

\subsection{Flexural Strength}

The maximum ultimate flexural strength $\left(5.26 \mathrm{~N} / \mathrm{mm}^{2}\right)$ of concrete beam was obtained in the case of PFC-10T. The flexural strength increase was on par for all fiber substituted concrete mixes and more specifically for tension confined fiber concrete systems. However, the flexural strength increase was optimal only at $0.1 \% \mathrm{~V}_{\mathrm{f}}$ of the plastic fiber substituted concrete mixes and this improvement was conspicuous for all plastic fiber substituted concretes.

\subsection{Crack Width}

The maximum crack opening at complete failure depends on the maximum fiber availability and the type of fiber confinement. Hence, the maximum fiber volume $(0.15 \%)$ provided the maximum crack width $(3.15 \mathrm{~mm})$ until complete failure, which was evidently 
noted for the PFC-15T concrete mix. It can be also seen that the maximum crack width is a function of fiber volume at the crack front. Compared to homogenous fibers aligned in a random orientation, the effective fibers present in the tension zone were more effective in post elastic deformation.

\subsection{Residual Flexural Strength Capacity}

The strength retaining capacity of concrete specimens when subjected to $95 \%$ of ultimate flexural loading and thereafter unloading to initial reloading cycles until failure were analyzed. As anticipated, the tension zone confined fiber concrete systems showed the maximum residual strength of $4.37 \mathrm{~N} / \mathrm{mm}^{2}$ at $0.15 \% \mathrm{~V}_{\mathrm{f}}$ of plastic fiber substitution. It was also well noted that fibers actively participated in load sharing along the beam axis. More specifically, the effective fiber volume in the aligned tension direction could provide adequate load resistance at cracking.

\subsection{Flexural Toughness}

The variation of flexural parameters for different fiber incorporated concrete mixes is shown in Figure 15. Similarly, the total energy absorbed (toughness) was calculated from the load-CMOD curves for various fiber concrete mixes as shown in Figure 16. Maximum flexural toughness of $33.43 \mathrm{~N}-\mathrm{m}$ was noticed for the PFC-15T concrete mix, which contained the maximum fiber volume fraction and fibers were confined in the tension zone. As anticipated, all the plastic fiber concrete mixes showed consistently increased toughness due to plastic straining of the plastic fibers at yielding. This test observation was similar compared to the addition of polypropylene fibers at $0.20 \% \mathrm{~V}_{\mathrm{f}}$, which exhibited an increasing trend of toughness values and in the case of steel fiber addition at $1.5 \% \mathrm{~V}_{\mathrm{f}}$, up to $135 \%$ due to the high modulus fibers and further crack propagation resistance [27].

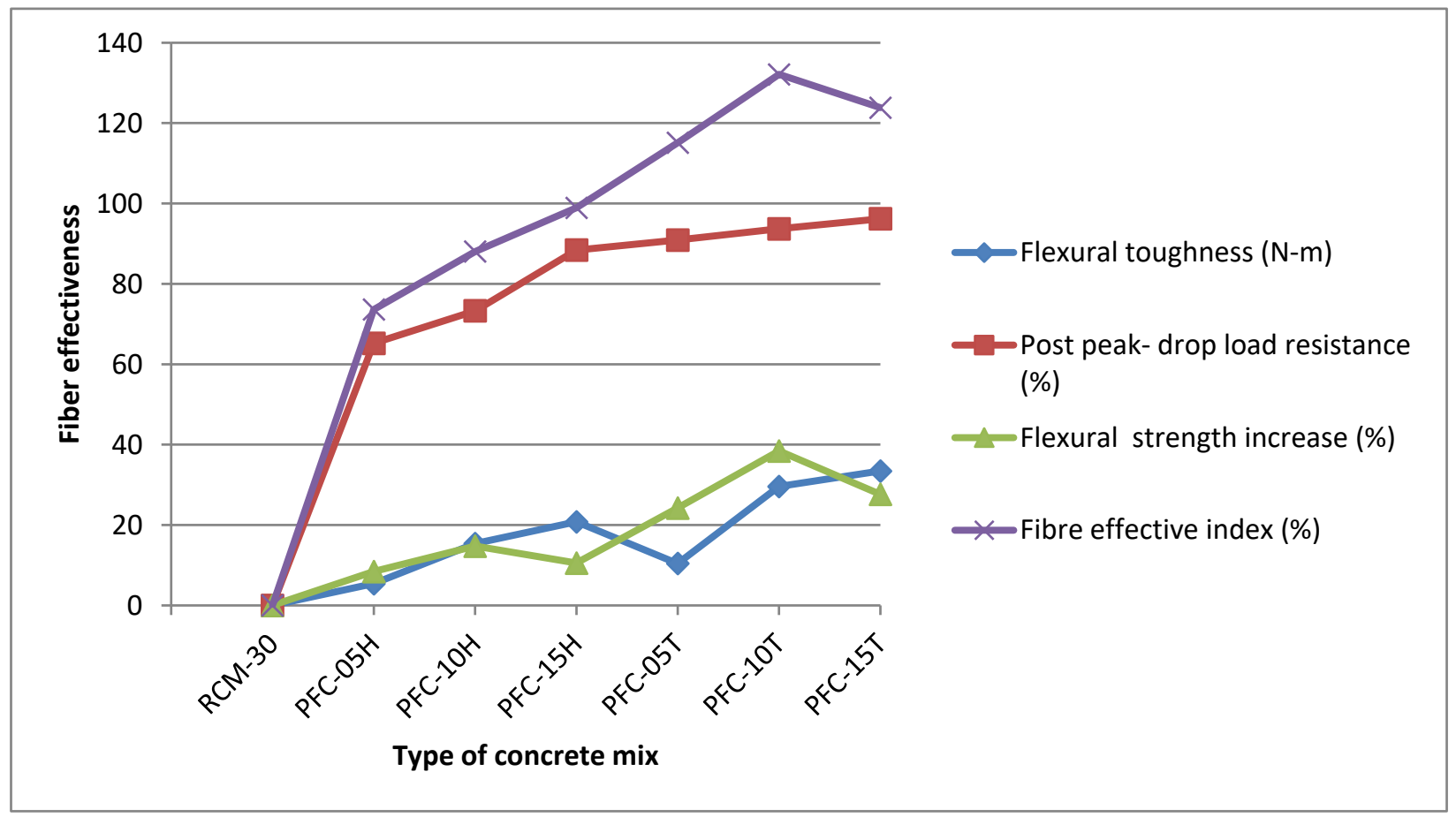

Figure 15. Fiber effectiveness for various flexural parameters of concrete mixes.

\subsection{Post-Peak Drop Load Resistance}

The real merits of fiber addition helps in crack bridging at large crack widths, thereby developing post crack resistance for improved post crack load carrying capacity. The experimental test results clearly indicated that homogenous fiber concrete mixes showed 
a sudden drop in load after reaching peak load, and this loss was very sudden for low fiber volume substituted concretes. With higher fiber volume, the maximum drop load resistance of $88.4 \%$ was obtained for homogenous fiber concrete $(\mathrm{PFC}-15 \mathrm{H})$. However, most importantly, for the same fiber volume when the fibers were confined in tension zone provedto be more effective with a maximum drop load resistance of $96.2 \%$ for the PFC-15T fiber concretes. This essentially justifies that high fiber volume accompanied by placing effective fibers in the tension confined zone dramatically improves the load resistance even after failure.

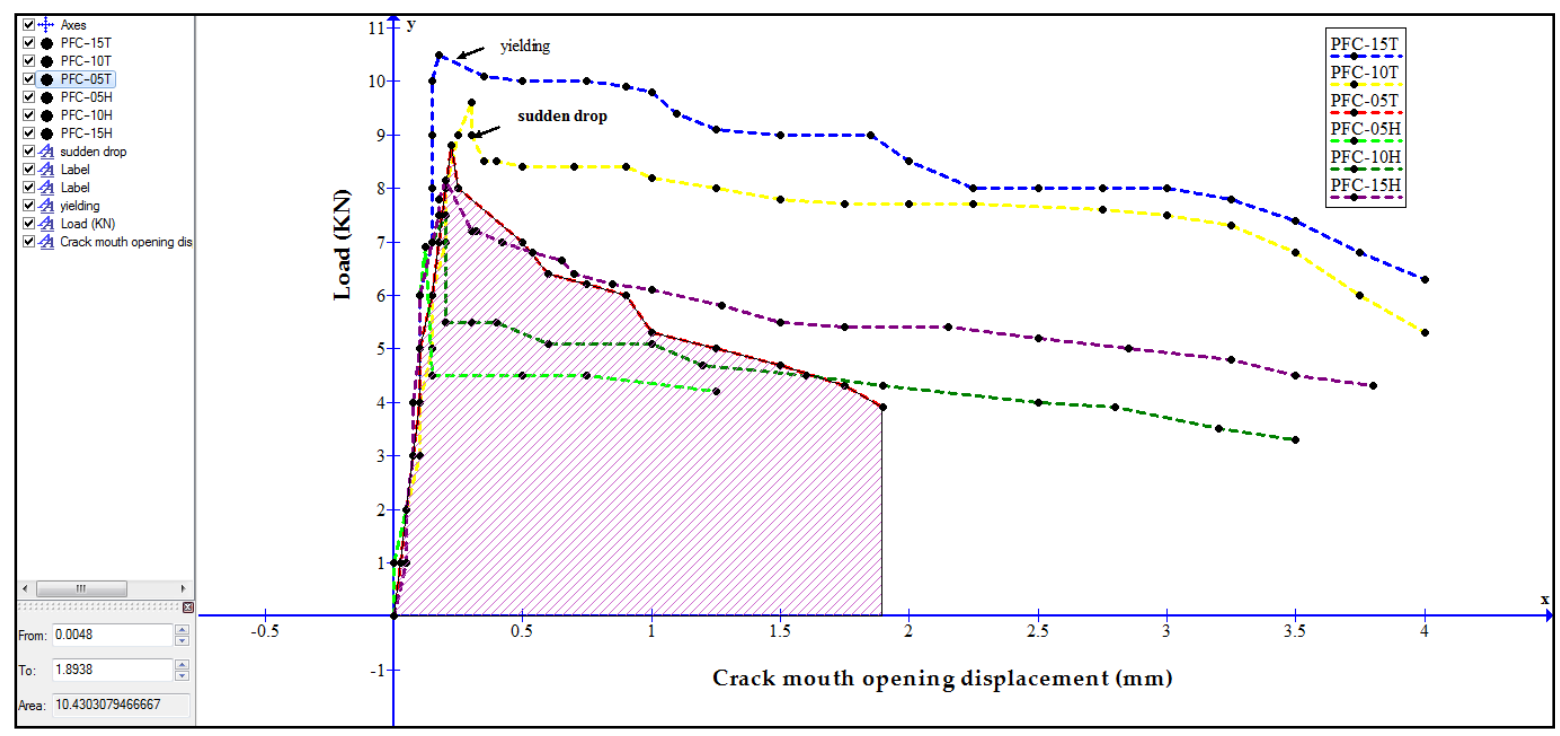

Figure 16. Flexural toughness calculation from load-CMOD plots of various concrete mixes.

\subsection{Fiber Effective Index}

The additive increase in the flexural strength and absolute toughness of plastic fiber concretes compared to the reference concrete were indicative of the overall performance of plastic fibers in concrete. Test results indicated that the performance index of tension zone confined concretes were consistently higher than homogenous fiber concrete mixes. The maximum fiber effective index of $132.12 \%$ was attained at an optimal fiber volume of $0.1 \%$ for the tension zone confined concretes whereas a maximum value of $98.93 \%$ was obtained for homogenous fiber concretes. This draws a subjective conclusion that effective fibers confined in tension zone at optimal volume fraction of $0.12 \% V_{f}$ were advantageous in improving the mechanical properties of the fiber incorporated concrete composites.

\section{Discussion}

Flexural parameters of the various plastic fiber reinforced concrete mixes were analyzed systematically. The fiber reinforcing effects in flexural bending were better realized in terms of fiber proportions and alignment of fibers. Test results proved to be satisfactory in terms of fiber reinforcing efficiency in the concrete matrix to enhance the bending characteristics of fiber concrete composites. The wide range of fiber performance index for the different concrete mixes tested is summarized in Table 7, which clearly indicates the reinforcing efficiency of plastic fibers. Flexural bending resistance is a characteristic property of concrete subjected to brittle failure mode without any impending warning to failure. The distinctive pre-peak and post-peak regions of load-deformation curves were dominated by the presence of discrete plastic fibers. However, the influence of fiber distribution had relative merit on the deformation characteristics of the fiber composites. Plastic fibers distributed homogenously and randomly oriented in the entire concrete mass showed a gradual increase in the various flexural parameters tested. Comparative assess- 
ments between randomly distributed and tension confined plastic fibers were speculative in terms of overall flexural improvements compared to the reference plain concrete. The inclusion of plastic fibers was promising in terms of delayed crack propagation and crack controlling mechanism, thereby enhancing the composite flexural strength characteristics. However, the importance of the present study indicates the mechanical properties of concrete typically consisting of effective fiber volume concentrated in the tension zone of the concrete beam. Experimental results revealed that the discrete plastic fibers play a critical role in developing a crack delaying process at the onset of loading. The fibers tend to share the load with the resultant increase in the elastic modulus of concrete. Additionally, the load deformation curves of the concrete beam sections were found to be steeper according to the increased fiber volume fractions in the concrete. The mechanistic fiber distribution and variations between the homogenous and tension confined plastic fibers were clearly evident from the post peak deformation characteristics. It can be seen that the plastic fibers had a self-straining capability of $52 \%$, which was better utilized when the plastic fibers were aligned in bending tension. This characteristic alignment of plastic fibers in the tension zone can enable the composite ductility at post peak yielding. Most importantly, the large presence of plastic fibers in the tension zone results in increased post cracking stress capacity without a sudden drop in load resistance. Failure of brittle concrete specimens is commonly characterized with a sudden drop in load carrying capacity at ultimate load. Homogenous fiber inclusion in the concrete system provides random orientation of fibers in a 3-dimensional plane. However, these fibers do not contribute effectively as in the case of aligned fibers due to an ineffective stress sharing mechanism. The delayed initiation of micro cracks and further propagation of cracks are intercepted by effective fiber spacing and orientation. The aligned fibers, in general, share the effective stress and reduce the stress buildup in the matrix, resulting in the delay of the origination of micro-cracks.

\section{Conclusions}

The following conclusions were arrived at based on the experimental observations obtained from this study. Shredded plastic waste fibers obtained from domestic waste plastic bottles were used in the production of two different types of concrete systems:(i) homogenously distributed in entire volume of concrete sections, and (ii) plastic fibers confined in the tension zone of concrete beam sections. Experimental tests were conducted on these concrete systems in compression and flexural bending and the test observations are summarized below:

(a) Stress-strain characteristics of fiber incorporated concretes up to $0.15 \% \mathrm{~V}_{\mathrm{f}}$ in compression were appreciably improved with a higher compressive strength of $33.20 \mathrm{~N} / \mathrm{mm}^{2}$ and post-peak compressive toughness of $357.75 \mathrm{~N}-\mathrm{m}$.

(b) Maximum absolute toughness of $516.38 \mathrm{~N}-\mathrm{m}$ was reported in the case of plastic fiber substituted concrete mixes (PFC-10H) with a toughness increase up to $321 \%$.

(c) Compressive failure modes were typically controlled with visible multiple cracks on the surface. Post-peak toughness of concrete showed controlled deformation without sudden failure due to composite ductility of plastic fibers in the matrix.

(d) Flexural evaluations of plastic fiber incorporated concrete mixes placed either homogenously or tension zone confined concretes were beneficial in improving the bending properties of concrete. However, the effective fibers placed in the tension zone appreciably contributed to the overall increase in the flexural parameters. Plastic fiber incorporation at $0.15 \% \mathrm{~V}_{\mathrm{f}}$ in concrete mixes resulted in maximum flexural toughness of $33.43 \mathrm{~N}-\mathrm{m}$ and maximum residual strength of $4.37 \mathrm{~N} / \mathrm{mm}^{2}$.

(e) All the flexural test properties were consistently increased when the total fiber volume was confined in the tension zone due to the effective load sharing capability of fibers as well as the maximum fiber availability. Plastic fibers control the sudden growth of cracking inside the matrix before reaching the ultimate load, thereby exhibiting an improved post-crack toughness. 
(f) The optimal plastic fiber volume $\left(0.10 \% \mathrm{~V}_{\mathrm{f}}\right)$ is promising in contributing to the fiber reinforcing efficiency in the matrix and crack bridging mechanism, providing maximum stress carrying capacity. Maximum flexural strength $\left(5.26 \mathrm{~N} / \mathrm{mm}^{2}\right)$ and post peak drop load resistance $(96 \%)$ were obtained in the tension zone confined concrete compared to full depth homogenous fiber reinforced concretes.

Author Contributions: Conceptualization, S.A. and M.A.; Methodology, S.A. and M.A.; Investigation, S.A. and M.A.; Writing-original draft, S.A. and M.A.; Writing-review \& editing, S.A. and M.A.; Funding acquisition, S.A. and M.A. Both authors have read and agreed to the published version of the manuscript.

Funding: This research was funded by the Deanship of Research, King Khalid University, Grant no.12 and the APC was funded from the research grant.

Data Availability Statement: Experimental datas are presented clearly in the graphical format and Tables in the manuscript as well as the procedure for test measurements and calculation is presented clearly for each test methods.

Acknowledgments: The authors gratefully acknowledge the Deanship of Research, King Khalid University for providing financial support for this sponsored research project.

Conflicts of Interest: The authors declare no conflict of interest.

\section{References}

1. Siddique, R.; Khatib, J.; Kaur, I. Use of recycled plastic in concrete: A review. Waste Manag. 2007, 28, 1835-1852. [CrossRef] [PubMed]

2. Zhao, K.; Chen, W.; Yang, D.; Zhao, W.; Wang, S.; Song, W. Mechanical tests and engineering applicability of fibre plastic concrete used in tunnel design in active fault zones. Tunn. Undergr. Space Technol. J. 2019, 88, 200-208. [CrossRef]

3. Khalid, F.S.; Irwan, J.M.; Ibrahim, M.W.; Othman, N.; Shahidan, S. Performance of plastic wastes in fiber reinforced concrete beams. Constr. Build. Mater. J. 2018, 183, 451-464. [CrossRef]

4. Saikia, N.; Brito, J.D. Mechanical properties and abrasion behaviour of concrete containing shredded PET bottle waste as a partial substitution of natural aggregate. Constr. Build. Mater. 2014, 52, 236-244. [CrossRef]

5. Islam, J.; Meherier, S.; Islam, A.K.M.R. Effects of waste PET as coarse aggregate on the fresh and hardened properties of concrete. Constr. Build. Mater. 2016, 125, 946-951. [CrossRef]

6. Fernando, F.; Saverio, S.; Valentino, P.B. Effects of recycled PET fibres on the mechanical properties and seawater curing of Portland cement-based concretes. Constr. Build. Mater. 2014, 61, 293-302.

7. Ismail, Z.Z.; Al-Hashmi, E.A. Use of waste plastic in concrete mixture as aggregate replacement. Waste Manag. 2007, 28, 2041-2047. [CrossRef]

8. Hosseini, S.A. Application of various types of recycled waste materials in concrete constructions. Adv. Concr. Constr. 2020, 9, 479-489.

9. Fahad, K.A.; Iqbal Khan, M.; Gurmel, G.; Samir, D. Production of Recycled Plastic Aggregates and Its Utilization in Concrete. Mater. Civ. Eng. J. 2016, 29, 04016248.

10. Basha, S.I.; Ali, M.R.; Dulaijan, S.U.A.; Maslehuddin, M. Mechanical and thermal properties of lightweight recycled plastic aggregate concrete. J. Build. Eng. 2020, 32. [CrossRef]

11. Tadepalli, P.R.; Mo, Y.L.; Hsu, T.T. Mechanical properties of steel fibre concrete. Mag. Concr. Res. J. 2013, 65, 462-474. [CrossRef]

12. Sukontasukkul, P.; Pongsopha, P.; Chindaprasirt, P.; Songpiriyakij, S. Flexural performance and toughness of hybrid steel and polypropylene fibre reinforced geopolymer. Constr. Build. Mater. J. 2018, 161, 37-44. [CrossRef]

13. Beglarigale, A.; Yazici, H. Pull-out behavior of steel fiber embedded in flowable RPC and ordinary mortar. Constr. Build. Mater. J. 2015, 75, 255-265. [CrossRef]

14. Bhogayata, A.; Arora, N.K. Impact strength, permeability and chemical resistance of concrete reinforced with metalized plastic waste fibers. Constr. Build. Mater. J. 2018, 161, 254-266. [CrossRef]

15. Mohammadhosseini, H.; Tahir, M.M.; Sam, A.R. The feasibility of improving impact resistance and strength properties of sustainable concrete composites by adding waste metalized plastic fibres. Constr. Build. Mater. J. 2018, 169, 223-236. [CrossRef]

16. Ghorpade, V.G.; Rao, H.S. The behaviour of Self Compacting Concrete with Waste Plastic Fibers When Subjected to Chloride Attack. Mater. Today Proc. 2018, 5, 1501-1508.

17. Usman, M.; Farooq, S.H.; Umair, M.; Hanif, A. Axial compressive behavior of confined steel fiber reinforced high strength concrete. Constr. Build. Mater. J. 2020, 230, 117043. [CrossRef]

18. Richardson, A.E.; Landless, S. Synthetic fibres and steel fibres in concrete with regard to bond strength and toughness. Built Environ. Res. 2009, 2, 128-140.

19. Susetyo, J.; Gauvreau, P.; Vecchio, F.J. Cracking behavior of steel fiber-reinforced concrete members containing conventional reinforcement. ACI Struct. J. 2011, 108, 488-496. 
20. Chan, S.Y.N.; Feng, N.Q.; Tsang, M.K.C. Durability of high-strength concrete incorporating carrier fluidifying agent. Mag. Concr. Res. J. 2009, 52, 235-242. [CrossRef]

21. Kazmi, S.M.; Munir, M.J.; Wu, Y.F.; Patnaikuni, I.; Zhou, Y.; Xing, F. Axial stress-strain behavior of macro-synthetic fiber reinforced recycled aggregate concrete. Cem. Concr. Compos. J. 2019, 97, 341-356. [CrossRef]

22. Panyakapo, P.; Panyakapo, M. Reuse of thermosetting plastic waste for lightweight concrete. Waste Manag. 2008, 28, 1581-1588. [CrossRef] [PubMed]

23. ASTM C39/C39M. Standard Test Method for Compressive Strength of Cylindrical Concrete Specimens; ASTM International: West Conshohocken, PA, USA, 2018.

24. Rilem, T.C. Determination of the fracture energy of mortar and concrete by means of three-point bend tests on notched beams. Mater. Struct. 1985, 18, 285-290.

25. Khatab, H.R.; Mohammed, S.J.; Hameed, L.A. Mechanical Properties of Concrete Contain Waste Fibers of Plastic Straps. Mater. Sci. Eng. 2019, 557, 012059. [CrossRef]

26. Zhi, G.; Renjuan, S.; Kun, Z.; Zhili, G.; Pengcheng, L. Physical and mechanical properties of mortar using waste Polyethylene Terephthalate bottles. Constr. Build. Mater. 2013, 61, 81-86.

27. Nibudey, R.N.; Parabat, D.K.; Pande, A.M. Strength Prediction of Plastic fiber Reinforced concrete (M30). Int. J. Eng. Res. Appl. 2013, 3, 1818-1825. 